\title{
CORRESPONDENCE.
}

\section{ON MR. STEPHENSON'S THEORY OF OPTIONS.}

To the Editor of the Assurance Magazine.

Sir,-As I think it possible that your readers may have had nearly enough of this subject, I will be as brief as I can in my reply to the two points raised in Mr. Stephenson's letter in the last Number of the Journal. 
Mr. S. asserts that I have altered the eonditions of his problem. This I deny. His formula is deduced upon the supposition that $P_{x}$ is deposited at interest; and, therefore, at the moment of death there will be due to the depositor's estate $\mathbf{P}_{x}$ plus the interest accruing from the commencement of the year of death. But this is precisely the same thing as $\mathrm{P}_{x}(\mathbf{1}+i)$, or $\mathrm{P}_{x}$ with a year's interest, payable at the end of the year of death; which, in accordance with the usual practice, I assumed in my problem.

Mr. S. further states, that in my remark respecting the "value of the policy" the possibility of deteriorated health is left out of consideration. Quite true; it is left entirely out of consideration, along with everything else which has nothing to do with the question I have raised. Any reader who may have taken the trouble to follow my reasoning will have noted that I mention the "value of the policy" merely to account for the possibility of effecting the assurance without parting with the control over the premium, and will not need any further explanation of the sense in which the expression is used.

If, instead of stating his problem as he has-viz., "to find the premium" required for the assurance, with the option of withdrawal-Mr. Stephenson had simply undertaken to show how the assurance might be effected so as to reserve to the policyholder the control over the premium paid, he would have aroided laying himself open to the exception I have taken. His mode of stating the problem, however, showed clearly that his notions on the subject were radically wrong; that he supposed the option of withdrawal to be a benefit included, and charged for, in the premium; and if any further proof of this were required, it is amply supplied in his last letter.

One more shot-not at Mr. Stephenson (who is a stranger to me) but at his theory-and I shall trouble neither your readers nor myself any further with the matter. He says that the value of the annuity, with $\mathbf{P}_{x}$ returnable at or before death is $\frac{\mathrm{N}_{x+n}}{\left(\mathrm{~N}_{x}-\mathrm{N}_{x+n}\right) i+\mathrm{D}_{x+n}}$. This expression I have shown is the value of the annuity, with $\mathrm{P}_{x}$, and a year's interest on it, returnable at the end of the year of death. But $\mathbf{P}_{x}$ with a year's interest at the end of the year of death, is equivalent to $\mathrm{P}_{x}$ with balf a year's interest at the moment of death ; so that, according to Mr. Stephenson,

1. A deferred annuity,

2. The return of the premium at death, and

3. The option of previous withdrawal,

are together equal in value to

1. A deferred annuity,

2. The return of the premium at death, and

3. Half a year's interest on the preminm, at death.

Here, then, we have it at last. The option of withdrawing the premium any time before death (and before the expiration of $n$.years), is equivalent to half a year's interest upon it payable at death within the same period!

$$
\text { I remain, Sir, }
$$

Your very obedient servant,

London, 1 st November, 1865.

W. M. MAKEHAM. 